\title{
Reidentifying Archaeoastronomy
}

\author{
Anthony Aveni \\ Russell Colgate Distinguished University Professor of Astronomy, Anthropology and Native American \\ Studies, Colgate University \\ aaveni@colgate.edu
}

"Interpretative (post-processual) archaeoastronomy" and "cultural astronomy" are relatively recent terms that reflect attempts to re-envision what I termed "green" and "brown" archaeoastronomy 35 years ago (Aveni 1989), after the colours of the Oxford I conference proceedings volumes. Unfortunately, most non-anthropological readers missed my subtle reference to Levi-Strauss' (1964) structural anthropological contrast between the raw and the cooked. Prehistoric (green) astronomy would always remain in the raw (uncooked) state because of too little cultural evidence available to process it, while case studies developed in societies with a written/iconographic record (e.g. the Maya) were more capable of phrasing/responding to social questions: such cases could thus be better prepared (i.e. cooked or "done", as Levi-Strauss put it).

The sort of archaeoastronomy Ruggles addresses in his paper "Pushing Back the Frontiers or Still Running Around the Same Circles? 'Interpretative' Archaeoastronomy Thirty Years On" (Ruggles 2011) still deals largely (though less so 30 years on) with the unwritten (ahistorical) record. Its outlets consist primarily of publications in specialised journals, e.g. Archaeoastronomy, Journal of Astronomy in Culture and the now defunct Supplement to the Journal for the History of Astronomy $(J H A)$, the last of these originally having been deliberately separated from the standard historical journal (now reintegrated, JHA accepts relatively few cultural astronomy papers). Other presentation outlets include SEAC, ISAAC and the Oxford Conference Series, which I initiated (Aveni 1989, ix) - all run largely by scientifically trained individuals and fostered by the professional astronomical societies.

By and large, astronomers find cultural astronomy irrelevant to their sphere of inquiry. For them it is interesting and entertaining, but largely a sideshow because it does not deal with questions - important historical ones, and here Ruggles and I agree - that they care to ask. (I base my observation on residence for more than 50 years in an excellent academic physics-astronomy department with which I have had cordial relations.) The present condition results in a relatively isolated community of individuals. In stark contrast, most significant contributions to New World cultural astronomy are published 
in peer-reviewed archaeological and anthropological journals, such as American Antiquity, Latin American Antiquity and Current Anthropology.

In part because of this unfortunate isolationist dilemma (cf. e.g. Silva and Campion 2015), the archaeoastronomy / cultural astronomy regarding which Ruggles raises questions is, in my view, not sustainable "in its own right" (Ruggles 2011, 6), nor do I recommend it be further developed as "a mini-discipline with a distinct theoretical basis of its own" (Ruggles 2011, 6). I see it more as a "set of methods, techniques and skills" (Ruggles $2011,6)$ that can be used by social scientists when they need them (like calling a mechanic when your car breaks down). A more productive scenario would involve one engaging the social science community and working together to solve a problem, as indeed has Ruggles. The ideal, if professionally risky, option would find individuals originally trained in science becoming well enough acquainted with anthropological/archaeological/ ethnohistorical method and theory to be able to work collaboratively at a deeper level to frame the kinds of questions Kintigh (1992; cf. Aveni 1992) suggests need to be asked. The last constitutes nothing short of a wholesale disciplinary transplant on the part of the participant, which removes the need to continually re-identify oneself and to struggle to lay out turf within the cracks of the disciplinary floorboards in order to set up one's domain. Ruggles, who views the archaeoastronomer as "a variety of archaeologist/ anthropologist/historian focused upon a particular set of cultural questions" (Ruggles 2011, 7), apparently would agree. Still, his concern with the identity struggle persists.

While I agree with much of what he says, I haven't the space here to take up certain important methodological issues Ruggles raises. Like him, I have weighed in on unfortunate archaic terminologies that yet bog us down: e.g. "observatories" (Aveni 2010, 127; Ruggles 2011,3) and "maps" (Aveni 2009, 58-61; Ruggles 2011, 5), on both of which Ruggles gives a fairly balanced account. In his efforts to police the interdiscipline, however, he overuses terms such as "scientific rigour", "robust methodologies", "quantifiable" aspects and "scientific method" (Ruggles 2011, 13-15). His piece reflects the extant problem of finding interpretations of alignments that square with the often sparse knowledge of the cultures being studied. The overemphasis on scientific terminologies reveals a tension: perhaps his post-processual archaeoastronomy is still haunted by the threat alternative archaeoastronomy (Campion 2015, 15-16) poses to the field being taken seriously by the archaeological-anthropological community. Yes, we all agree: grounding our hypotheses in social theory is no excuse for avoiding a scientific approach, though total data collection on carved rocks and shadows (see Ruggles 2011, 12-13 for his example) is not comparable to the study of an elaborately decorated skewed building regarding which culture-based data implies a possible relationship with a specific celestial construct.

To be specific, the Caracol is not a unique monument with a unique interpretation ( $a$ "one-off"). Neither is it unique in the sense that Venus alignments best account for its asymmetries; nor in that it is a round structure that incorporates astronomical alignments; nor is the interpretation of such alignments unique. Here, proofs of intentionality (Schaefer 2006) do not exist. The "one-off" problem is typical of that raised by critics of investigations of pictographs, petroglyphs and megalithic rings, which occur in abundance, relatively free of any robust cultural context. Repeatability is practically all you can look for. 
On Maya E Groups, Ruggles seems most concerned about the possibility of "a totally subjective reading of the evidence, in which those sites that have alignments can be interpreted as those with functioning observing devices, while the others can be interpreted as those that never needed them" (Ruggles 2011, 9). Such a reductive approach reflects his apparent lack of familiarity with the rather large body of culture-based data (overseen by the anthropology police) affecting our understanding of the complex nature of such structures (e.g. the ongoing Santa Fe Institute conferences on E-group complexes - cf. most recently Freidel and Chase, in press).

Despite its difficulty penetrating the anthropological-archaeological disciplines, slow progress has been made in archaeoastronomy since the old days of alignment hunting in one's spare time. Thomas' (2002) assessment of the Dorset Cursus with its coincidence of sunset, the dead in their barrow, the chalk and the forest joining earth, sky, life and death, past and present, is an excellent example of situating the skyscape in broader context. I find Thomas' parallel in recent studies of the Teotihuacan grid (e.g. Carrasco and Sessions 2000), which incorporate cave, mountain and sky. In both instances, the astronomical component is removed from its privileged position in hypothesis generation.

North American studies have progressed as well. Let me offer a comparison of the two "Chaco phenomenon" volumes, especially the forewords, written 27 years apart by the same individual (Judge 1987, 2014). In the 1987 volume, archaeologist Jim Judge characterised archaeoastronomy as "a 'rediscovery' of the Sun's path by modern Anglo populations" (Judge 1987, 7). To the contrary, his preface to the 2014 volume acknowledges the proceedings as "a major step forward in the integration of archaeology and astronomy" (Judge 2014, xxii). From the standpoint of attendance, demographics alone, progress was made: while contributions to the 1987 volume by astronomers outnumbered those by archaeologists/anthropologists by nearly two to one, that ratio was reversed in the 2014 proceedings. The 2014 volume's content also reflected an increased emphasis on cultural context and a diminution of alignment studies and precisional overkill. (On the other hand, my own survey of presenters at Oxford II - excluding those on the Maya 2012 special session - showed 34\% astronomy, $45 \%$ anthropology and $21 \%$ other compared to $46 \%$ astronomy, $39 \%$ anthropology and $15 \%$ other at Oxford IX.)

Progress also holds true for the 2004 Fort Ancient Earthworks conference proceedings (Connolly and Lepper 2004), though I (Aveni 2004) felt compelled to note the perpetual invocation of solstices and lunistices (I have yet to find a lunar alignment or reference thereto in all of Mesoamerican astronomy). I added that were there any skyscape alignments at the sites investigated, they ought to respond to the specific needs of the people who lived in that place at that time. Since practically all of the Hopewell sites in the study are situated on the flood plains of the Little and Great Miami and Scioto rivers, where people grew the Eastern Agricultural Complex (including goosefoot, maygrass and sunflower), tended to the fish run, picked berries and other wild fruits and hunted wild animals, it would make sense that those who lived and worshipped there might, like the Anasazi (Aveni 2001, 40), have used the horizon position of the Sun to set out a specific range of dates that demarcated the hunting, fishing and planting seasons and the rites thereto appertaining. One wonders: are scientifically trained investigators deterred from such searches because they would have difficulty establishing results with precision? 
In sum, I continue to insist, as I did initially (Aveni 1979), that archaeoastronomy will better succeed when it is fully integrated into the culture-based disciplines. One must present papers and offer sessions at meetings in the parent disciplines, thus reducing, though certainly not eliminating, the frequency of and perceived need for archaeoastronomy meetings. As one conferee at the recent Chaco conference remarked: "Those who practice archaeoastronomy talk only to others doing archaeoastronomy, not to the larger community of anthropology and archaeology" (Munson et al. 2014, 159). Retooling to acquire theory and method in a base discipline other than one's own is no mean task. So, to three-dimensionalise Ruggles' circle, I believe the bubble encapsulating contemporary (especially) ahistorical archaeoastronomy is still there, but hopefully the membrane is wearing thin.

\section{References}

Aveni, A., 1979. "Archaeoastronomy Today". In Archaeoastronomy in the Americas, edited by R. Williamson, 25-28. Los Altos, CA: Ballena.

Aveni, A., 1989. "Wither Archaeoastronomy". In World Archaeoastronomy, edited by A. Aveni. 3-12. Cambridge: Cambridge University Press.

Aveni, A., 1992. "Nobody Asked, But I Couldn't Resist: A Response to Keith Kintigh on Archaeoastronomy and Archaeology". Archaeoastronomy and Ethnoastronomy News, 6: 1, 4 [online]. Accessed October 2015, http://terpconnect.umd.edu/ tlaloc/archastro/ae6.html

Aveni, A., 2001. Skywatchers. Austin: University of Texas Press.

Aveni, A., 2004. "An Assessment of Studies in Hopewell Astronomy". In The Fort Ancient Earthworks: Prehistoric Lifeways of the Hopewell Culture in Southwest Ohio, edited by R. P. Connolly and B. T. Lepper, 243-257. Columbus: Ohio Historical Society.

Aveni, A., ed., 2008. Foundations of New World Cultural Astronomy: A Reader with Commentary. Boulder: University Press of Colorado.

Aveni, A., 2009. The End of Time: The Maya Mystery of 2012. Boulder: University Press of Colorado.

Aveni, A., 2010. "Cosmology and Cultural Landscape: The Late Postclassic Maya of Yucatan". In Astronomers, Scribes, and Priests: Intellectual Interchange between the Northern Maya Lowlands and Highland Mexico in the Late Postclassic Period, edited by G. Vail and C. Hernandez, 115-132. Washington, DC: Dumbarton Oaks.

Campion, N., 2015. "Skyscapes: Locating Archaeoastronomy within Academia". In Skyscapes: The Role and Importance of the Sky in Archaeology, edited by F. Silva and N. Campion, 8-19. Oxford: Oxbow Books.

Carrasco, D. and S. Sessions, 2000. Mesoamerica's Classic Heritage. Boulder: University Press of Colorado.

Connolly, R. P. and B. T. Lepper, eds, 2004. The Fort Ancient Earthworks: Prehistoric Lifeways of the Hopewell Culture in Southwestern Ohio. Columbus: Ohio Historical Society.

Freidel, D. and A. Chase (in press). Early E Groups, Solar Calendars, and the Role of Astronomy in the Rise of Lowland Maya Urbanism: Proceedings of the Santa Fe Institute Conferences in Group E Complexes. Gainesville: University of Florida Press.

Judge, J. W., 1987. "Archaeology and Astronomy: A View from the Southwest". In Astronomy and Ceremony in the Prehistoric Southwest, edited by J. B. Carlson and W. J. Judge. Papers of the Maxwell Museum of Anthropology 2. Albuquerque, NM: Maxwell Museum of Anthropology.

Judge, J. W., 2014. "Foreword". In G. Munson, T. W. Bostwick and T. Hull, 2014. Astronomy and Ceremony in the Prehistoric Southwest: Revisited. Papers of the Maxwell Museum of Anthropology 9. Albuquerque, NM: Maxwell Museum of Anthropology. https://doi.org/10.1163/22105018-12340015

Kintigh, K. W., 1992. "I Wasn't Going to Say Anything, But Since You Asked". Archaeoastronomy and Ethnoastronomy News 5: 1, 4 [online]. Accessed October 2015, http://terpconnect.umd.edu/ tlaloc/archastro/ae5.html 
Levi-Strauss, C., 1964. The Raw and the Cooked. Chicago: University of Chicago Press.

Munson, G., T. W. Bostwick and T. Hull, 2014. Astronomy and Ceremony in the Prehistoric Southwest: Revisited. Papers of the Maxwell Museum of Anthropology 9. Albuquerque, NM: Maxwell Museum of Anthropology.

Ruggles, C. L. N., 2011. "Pushing Back the Frontiers or Still Running Around in the Same Circles? 'Interpretative Archaeoastronomy' Thirty Years On". In "Oxford IX" International Symposium on Archaeoastronomy, edited by C. L. N. Ruggles, 1-18. Proceedings of the IAU Symposium 278. Cambridge: Cambridge University Press. https://doi.org/10.1017/s1743921311012427

Shaefer, B. E., 2006. "Case Studies of Three of the Most Famous Claimed Archaeoastronomical Alignments in North America". In Viewing the Sky Through Past and Present Cultures: Selected Papers from the Oxford VII International Conference on Archaeoastronomy, edited by T. W. Bostwick and B. Bates, 27-56. Phoenix, AZ: City of Phoenix Parks Recreation and Library.

Silva, F. and N. Campion, 2015. Skyscapes: The Role and Importance of the Sky in Archaeology. Oxford: Oxbow Books.

Thomas, J., 2002. Understanding the Neolithic. London: Routledge. 